\title{
Implementation of M2M Communication Protocol for IoT Based Email System
}

\author{
Swatee D. Sonwane ${ }^{1}$, V. V. Kimbahune ${ }^{2}$ \\ ${ }^{1}$ Student, Department of Computer Engineering, SKN College of Engineering Savitribai Phule Pune University, India \\ ${ }^{2}$ Professor, Department of Computer Engineering, SKN College of Engineering Savitribai Phule Pune University, India
}

\begin{abstract}
The vision of internet of thing (IoT) is to collect and exchange data between the networks of physical objects, devices, vehicles, etc. This collected data from different devices and processed information from different source will control physical objects. To interact with the real world, these devices must work together with speeds, scales, and capabilities. To exchange and collect data from physical objects, there is a need of communication protocol. Hence this paper aims to utilize existing standard protocols to sustain smart IoT applications. This paper proposed an advance email system in which communication will be possible in both ways like, human to device and device to device. The tremendous amount of data which is generated by smart IoT devices (sensors) will be stored and processed within the cloud.
\end{abstract}

Keywords: IoT, Machine to Machine (M2M), Communication Protocol, Cloud, Email

\section{Introduction}

Now a days technology drift towards autonomous computing, sensing and performing actions based on decisions made by devices for various IoT applications such as smart cities, smart home, and smart environment, for business domain, M2M communication plays an significant role. This paper introduces comparative study between the Constrained Application Protocol (CoAP) and Hypertext Transfer Protocol (HTTP) and select communication protocol for this IoT based Email system. The CoAP is used as a communication protocol in this IoT based Email system to keep the system lightweight and suitable for constrained devices. This protocol is designed for Machine-to-machine (M2M) applications such as building automation and smart energy.

\subsection{Background}

There are standard protocols available for M2M communication that is discussed below;

\subsubsection{HTTP}

Under the framework of IP suite, HTTP is designed for application layer to support different devices such that laptop, phones and so on. HTTP is stateless protocol but it has some issues regarding resources. It is expensive as it requires more network resources and more code to be implemented. To presume reliability, HTTP uses transmission control protocol (TCP) as a transport layer protocol. As discussed before, HTTP requires more resources to execute, so in constrained environment it might not be useful.

\subsubsection{CoAP}

CoAP is a lightweight as well as stateless protocol. It is developed to support constrained devices as well as to overcome the problems regarding overhead arises in connection oriented protocol. CoAP uses user datagram protocol (UDP) as the transport layer protocol which is connectionless.

The main function of this Email system is that, whenever any event occurs, alerts are sent out via email. Multiple sensors are used to collect context information and that information processed and controlled through different sources. The storage and applications of IoT over the internet are accessed from different devices such that smart phones, laptoptop and so on. The proposed system aim's to provide cloud for storage purpose and fast retrieval of data. In future IoT can be viewed as interconnection of hundreds or thousands of end-devices. These devices require sensing, computing and communication capabilities over the Internet. The cellular as well as radio technologies help these devices to connect to internet. The devices at the base level send data to associated web server which is ubiquitously accessible which would be deployed over cloud. The motive behind this is to increase availability of system.

\section{Research Motivation}

IoT networks form the connection between human and devices ubiquitously. There are billions of devices connected to each other so the data generated by these devices are also huge. There is need to store, process and analyze the data generated by those things. The devices like multi-sensors or actuator continuously send the information or alert messages. By using mail server, store data generated by these things and there is no need of special server for storing the information created by things. There is an exponential growth of email user is observed as 3.1 billion to 4.1 billion in last 4 years. If we integrate email system and the IoT, then it will be useful for people to know about the IoT applications look like. As many people using Email accounts, it is useful to provide such, IoT based Email system to create their own IoT applications. 


\section{International Journal of Science and Research (IJSR) \\ ISSN (Online): 2319-7064}

Index Copernicus Value (2013): 6.14 | Impact Factor (2015): 6.391

\section{Related Work}

As per a recent study, in paper [1] Asma Elmangoush and Ronald Steinke proposed that M2M platform is used to connect increasing number of devices efficiently and the data generated by these devices are exchanged between smart services. In this paper, they proposed one architecture which is used to maintain various services and traffic. In paper [2] Angelo and Mattia implemented CoAP using the protocol for constrained world. Survey regarding IoT takes place in various papers; in paper [3] Charith Perera and Chi Harold Liu presented a survey of the IoT solutions in the emerging marketplace. In paper [4], Ovidiu Vermesan and Peter Friess introduces how to recover the effectiveness of complex tasks. Some survey shows solution to manage tremendous data generated due to billions of connected devices, in paper [5] , Shifeng Fang and $\mathrm{Li} \mathrm{Da} \mathrm{Xu}$ proposed that as IoT devices increasing day by day, users face problems to handle these devices. This paper defines a relationship to detect fault points in IoT devices and proposed mechanism for detecting fault point. This paper demonstrates implementation of CoAP to support low power and low rate devices.

\subsection{Technologies about iot}

IoT is the current technology in the domain of pervasive computing, which extends to mobile and communication network. IoT plays a vital role in the business domain which will lead to economic growth. According to the Forrester which consults U. S. Authority predicts the future of IoT as 30 times larger networks than internet in the upcoming 5 years as well as their will be up to 50 billions connected nodes. In IoT systems, there is large use of sensors and interface devices having electronic labels will be comparatively larger than the smart devices. The development of IoT is going on very smooth way which will generate high revenue in terms of trillions of financial benefits. One of the motive of IoT system is betterment of life which will lead to exponential growth in the business domain. IoT is rising communication network and has a bright future, at the same time we need to face some challenges regarding standardization, security, support to legacy systems, policy control and so on. IoT is in its initial phase of establishment and still requires few years to establish it in a very organized manner because we can say IoT is convergence of various technologies. Even the technologies which are part of IoT are also not established very well. The IoT implementation requires strong political, social and national interest and mutual efforts of various service providers.

\subsection{Technologies about messaging}

Audio, text, video uses IM (Instant Messaging) to communicate on the network and, deliver audio, text, and video As instant audio, instant text and instant video using protocol. There are lots of instant messenger available in the market such as MSN, Google Talk, and Yahoo, which consist of a number of different features such as online Messaging, video chatting, and so on. IM is used by different enterprise customer services, eCommerce, etc. IM Available for communication takes place between peoples, but still it is not available for things. So in future, IM will focus on communication takes place between things and combine IM with IoT.

\section{Evaluation of Related Work}

According to survey, there are number of IoT solutions present, this system proposed IoT based Email system to create IoT applications. The main goal of M2M platform is to create efficient connection between devices, table below shows comparative study between HTTP and CoAP which are available for $\mathrm{M} 2 \mathrm{M}$ communication. As seen in the below table, HTTP uses TCP (transport control protocol), CoAP uses UDP (user datagram protocol). TCP is connection oriented, reliable protocol but it has overhead so it is not suitable for M2M communication. UDP is connectionless, unreliable protocol, so that CoAP uses its own mechanism to achieve reliability. As HTTP uses TCP, it required large message size to transfer messages and CoAP uses 4 Byte header to transfer the message.

Table 1: Comparison between M2M communication protocols

\begin{tabular}{|c|c|c|}
\hline $\begin{array}{l}\text { Protocol } \\
\text { Description }\end{array}$ & $\begin{array}{c}\text { HTTP FOR } \\
\text { IoT Communication }\end{array}$ & $\begin{array}{c}\text { CoAP for } \\
\text { IoT Communication }\end{array}$ \\
\hline $\begin{array}{c}\text { Internet } \\
\text { Standards use }\end{array}$ & $\begin{array}{l}\text { HTTP uses IETF } \\
\text { standard }\end{array}$ & $\begin{array}{l}\text { CoAP also uses IETF } \\
\text { standard }\end{array}$ \\
\hline \begin{tabular}{c|} 
Transport \\
Layer \\
Protocol \\
\end{tabular} & TCP & UDP \\
\hline $\begin{array}{l}\text { Messaging } \\
\text { Method }\end{array}$ & $\begin{array}{c}\text { Request/response } \\
\text { method is used in } \\
\text { HTTP }\end{array}$ & $\begin{array}{l}\text { Request/response method } \\
\text { is used in CoAP }\end{array}$ \\
\hline Message Size & Large & Small (header 4 Byte) \\
\hline Service Level & $\begin{array}{l}\text { Service level same to } \\
\text { all messages }\end{array}$ & $\begin{array}{c}\text { Uses two different } \\
\text { services that are } \\
\text { Confirmable and non- } \\
\text { confirmable. }\end{array}$ \\
\hline
\end{tabular}

In Gap analysis, we consider various factors which will describe about contribution in the proposed work. The main contribution in proposed system is to access devices and keeping track of Device to Device communication. When the proposed system takes any action related to devices, the notification is sent for user convenience. In proposing system the user can integrate various IoT related applications like smart home, smart office, smart city, etc. So that it can be a generic framework for application management which will decrease application management overhead. The email server is placed on cloud so it will give elasticity to the proposed system.

Table 2: Comparison between Existing and Proposed system

\begin{tabular}{|l|c|c|}
\hline \multicolumn{1}{|c|}{ Email systems } & $\begin{array}{c}\text { Existing } \\
\text { System }\end{array}$ & $\begin{array}{c}\text { Proposed } \\
\text { System }\end{array}$ \\
\hline Sms Notification & Yes & Yes \\
\hline Storage on Cloud & Yes & Yes \\
\hline Compatibility regarding IoT & No & Yes \\
\hline Integration of multiple Application & No & Yes \\
\hline $\begin{array}{l}\text { Provision to Device to Device communication } \\
\text { via Email }\end{array}$ & No & Yes \\
\hline Access Devices via Email & No & Yes \\
\hline
\end{tabular}

Volume 5 Issue 6, June 2016 www.ijsr.net

Licensed Under Creative Commons Attribution CC BY 


\section{International Journal of Science and Research (IJSR) \\ ISSN (Online): 2319-7064}

Index Copernicus Value (2013): 6.14 | Impact Factor (2015): 6.391

\subsection{COAP over HTTP in IoT communication network.}

In the TCP/IP protocol stack HTTP is present in the application layer. HTTP is widely used and powerful but at the same time it has a high cost in terms of implementation and resource usages. HTTP has a foundation of TCP protocol, which is reliable in nature. HTTP is widely used on different computing devices (smart phones, laptop, tabs). Due to resource demanding nature of HTTP it might not be suitable for M2M applications. HTTPS consider the security aspect of communication. When HTTP includes SSL as a component, then HTTP is ready for authentication mechanism making M2M solution secure. IoT devices have characteristics that they have low memory, low processing power, low lifetime, so it requires a lightweight HTTP library together with small SSL stack, it makes the programmer to design convenient HTTPS based M2M protocol. The web server can handle only HTTPS request not business logic for data management in connecting devices. Considering general scenario in which sending requests and receiving response from server is a tedious task because there are lots of commands exchanged between single HTTPS request/response over a communication medium. These problems are solved by one protocol this is nothing but CoAP. CoAP was designed to support constraind devices in constrained environment which have low computational as well as memory capabilities.

\section{Proposed Work}

IoT can be defining as billions of connected devices in the network. IoT plays an important role in day to day life. The proposed system is a combination of IoT and Email system called IoT based Email System. In present Email system, they provide human to human communication. Proposed email system will able to provide service for all IoT applications. This system adds some features in this IoT based Email system like human to machine as well as M2M communication. To form a communication between human to machine and $\mathrm{M} 2 \mathrm{M}$, there is a need of communication protocol. As discussed above for M2M communication there is need of a protocol which is lightweight and provide reliability, low overhead and minimum message size. Considering all these parameters, all above mention parameters are present in one protocol which is nothing but CoAP. To keep the implementation lightweight CoAP running over UDP. UDP is not reliable, but running on unreliable protocol CoAP uses its own mechanism for achieving reliability.

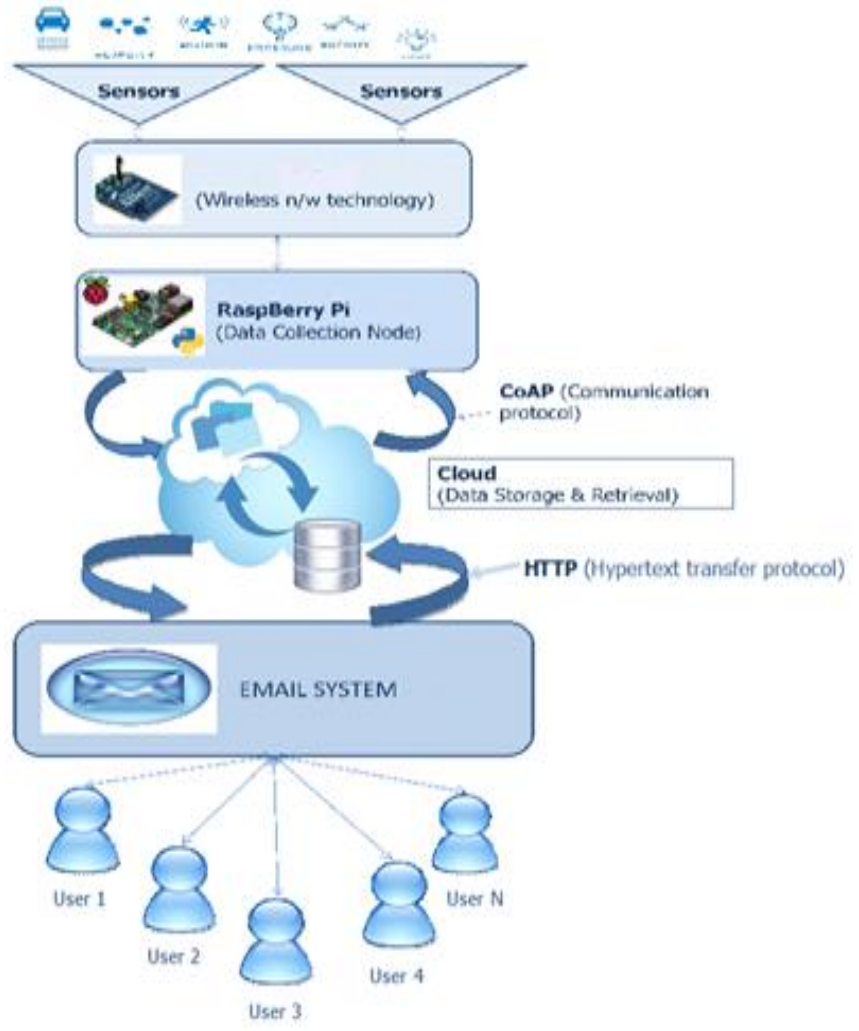

Figure 1: Proposed Architecture

As seen in above figure 1 , sensors are used to sense the data and send context information. Using wireless network technology the sensor data send to microcontroller. ZigBee, Bluetooth, Wi-Fi are wireless network technologies. ZigBee uses international standard IEEE 802.15.4. The range of ZigBee is 10 to 20 meters (approx). Bluetooth uses international standard IEEE 802.15.1 and having range less than $10 \mathrm{~m}$. Wi-Fi has the international standard IEEE 802.11 and having range $32 \mathrm{~m}$. Raspberry $\mathrm{Pi}$ is a data collection node and a controller, from this node the action is performed on devices. In this system, when user wants to control the device using Email, user will request to control device and action will be performed by Raspberry Pi to control those devices. We know that, billions of devices going to be connected to the network and the data which is going to generate will be huge. To handle such a tremendous amount of data there is a need of cloud. And UDP based CoAP is used to transfer this data into the cloud. Hosting an Email service on local system often sets a limit on how much can be stored on their server in those cases it is best to use a cloud service as it will provide flexibility to this system.

\subsection{Real Time Scenario}

Consider an example of any application of IoT such as smart home, smart city, smart office, etc., in which user will access their completely automated devices with the help of IoT enabled Email system. Decisions are taken on the basis of context awareness which is embedded in the system. The data generated by devices and sensors will be stored in the cloud. These data will help in better decision and prediction making, which will lead to intelligent, smart system. 


\section{International Journal of Science and Research (IJSR)}

ISSN (Online): 2319-7064

Index Copernicus Value (2013): 6.14 | Impact Factor (2015): 6.391

\section{Mathematical Modeling}

Consider IoT based Email system be $\mathrm{S}$.

- $\mathrm{S}=\mathrm{IoT}$ based email-System

Consider following Elements

- $\mathrm{S}=\{\mathrm{U}$, Fun, In, $\mathrm{O}\}$

Where,

$\mathrm{U}=$ user registered in this proposed Email system. $\mathrm{In}=$ User request for Inputs.

$\mathrm{O}=$ this system, giving response to the user request.

Fun=System provide some automatic function.

- $\mathrm{U}=\{\mathrm{u} 1, \mathrm{u} 2, \mathrm{u} 3 \ldots \ldots \mathrm{un}\}$

$>\mathrm{u} 1=$ Registered user 1 .

$>$ un=Registered user $n$.

- $F u n=\{f 1, f 2, f 3 \ldots \ldots f f n\}$

$>\mathrm{f} 1=$ Automatic mail transfer

$>\mathrm{f} 2=$ Automatic Device control

- $\operatorname{In}=\{\mathrm{i} 1, \mathrm{i} 2, \mathrm{i} 3 \ldots . . . \mathrm{in}\}$

$>$ i1=Request for Control devices(Things)

$>$ i2=Request for summary of e-app

$>\mathrm{i} 3=$ Request for Device information

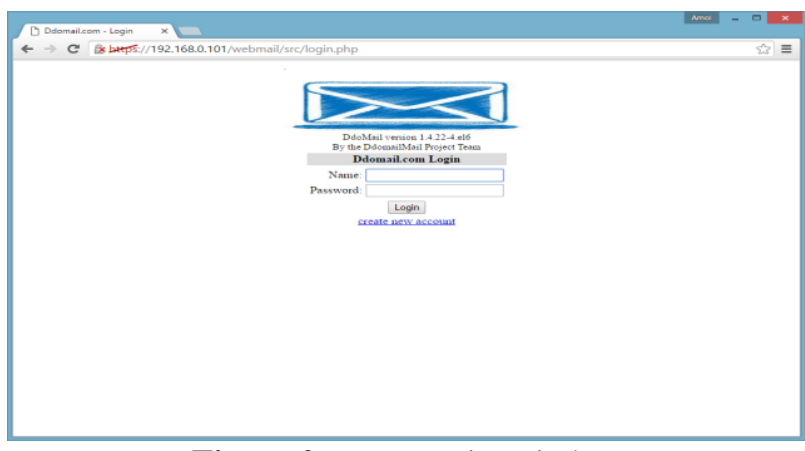

Figure 2: User Login Window

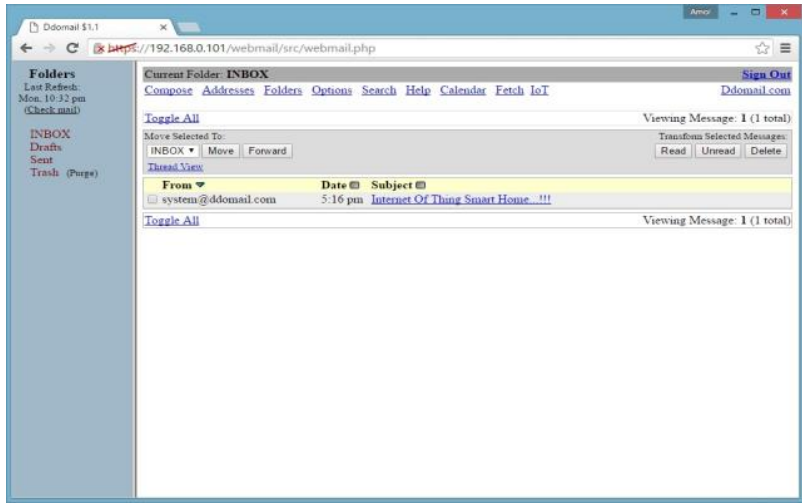

Figure 3: User Display Window

- $\mathrm{O}=\{01, \mathrm{o} 2, \mathrm{o} 3 \ldots \ldots$...on $\}$

o3=Display summary log of things

o4=device controlled

$\mathrm{x}: \forall \mathrm{e}_{\mathrm{i}} \in \mathrm{E}$

$>05=$ automatic device controlled

$\mathrm{Y}:=\left(\mathrm{e}_{\mathrm{i}} \rightarrow \mathrm{a}_{\mathrm{i}} \in \mathrm{A}\right) \wedge\left(\mathrm{d}_{\mathrm{i}}>\left(\mathrm{th}_{\mathrm{i}} \in \mathrm{THR}\right)\right) \rightarrow\left(\mathrm{nt}_{\mathrm{i}} \in \mathrm{NT} \wedge\right.$ Email $_{\text {min }}$

Where,

$a_{i}=\left\{\mathrm{a} 1=0 \mathrm{~N}^{\mathrm{a}} \mathrm{a} 2=0 \mathrm{FF}, \mathrm{a} 3=\right.$ Read, $\mathrm{a} 4=$ Write $\}$

$t h_{i}=\left\{t h_{k}, t h_{k+1}, t h_{k-n}\right\}$

$\mathrm{K}=1,2,3 \ldots \ldots \mathrm{n}$;

\section{Algorithm}

$\mathrm{E}=$ Set of Events

$\mathrm{D}=$ Set of Devices

$\mathrm{A}=$ Set of Action $\left\{\mathrm{a} 1=0 \mathrm{~N}_{s} \mathrm{a} 2=\mathrm{OFF}_{s} \mathrm{a} 3=\operatorname{Read}_{s} \mathrm{a} 4=\right.$ Write $\}$

$\mathrm{x}: \forall \mathrm{e}_{\mathrm{i}} \in \mathrm{E}$

$\mathrm{i}=1$

for $\mathrm{i}=1$ to $\mathrm{D}$;

if $\left(d_{\mathrm{i} \text { (Required_walue) }}>\left(\right.\right.$ th $\left.\left._{\mathrm{i}} \in \mathrm{THR}\right)\right)$

1] $Y:=\left(e_{i} \rightarrow a_{i} \in A\right)$

2] (send_packet(emailid, applid, thigid, thris ))

3] (send_notification(mail))

else

return;

\section{Result}

As shown below, the result displayed is taken by implementing project. Thus, device is automatically controlled by the Raspberry pi and the automatic notification is send when event is generated. And devices are controlled by user using IoT plugin.

\section{Volume 5 Issue 6, June 2016} www.ijsr.net

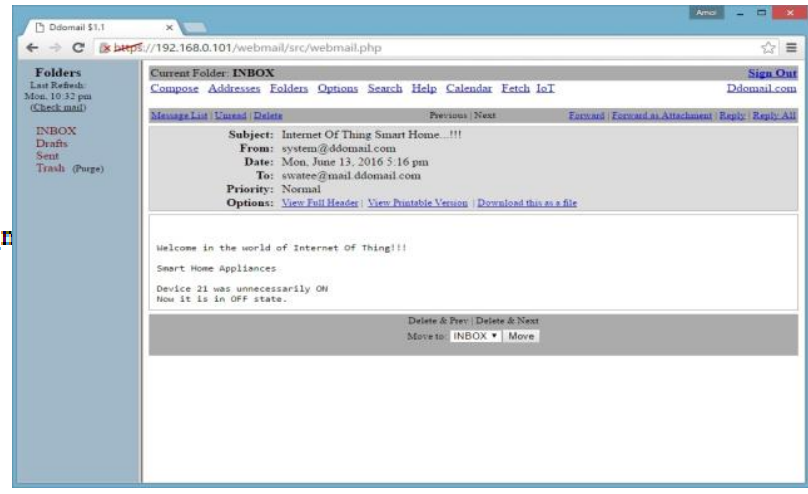

Figure 4: Automatic Generated Notification

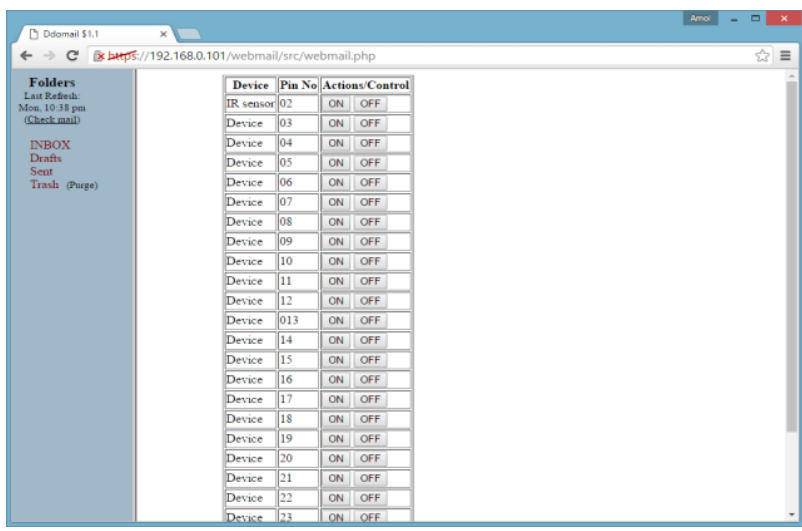

Figure 5: Devices controlling Window

\section{Conclusion}

From theoretical and practical literature of Email communication system, this paper describes an efficient applicability of various communication protocols under the 


\section{International Journal of Science and Research (IJSR) \\ ISSN (Online): 2319-7064}

Index Copernicus Value (2013): 6.14 | Impact Factor (2015): 6.391

umbrella of IoT. In the proposed system, IoT uses CoAP to support constrained devices and to make communication lightweight.

\section{Acknowledgement}

This work is sponsored by DSM Bhalerao Infotech, Mundhwa- Pune

\section{References}

[1] Asma Elmangoush, Ronald Steinke, Thomas Magedanz Technical University of Berlin Germany," Applicationderived Communication Protocol Selection in M2M Platforms for Smart Cities".IEEE 18th International Conference on Intelligence in Next Generation Networks (ICIN),2015, pp. 76-82.

[2] Angelo P. Castellani, Mattia Gheda, Nicola Bui, Michele Rossi, Michele Zorzi, Department of Information Engineering (DEI), University of Padova, Italy Web services for the Internet of Things through CoAP and EXI, conference paper," IEEE International Conference on Communications Workshops (ICC), 2011, pp. 1-6.

[3] Charith Perera, Chi Harold Liu, Srimal Jayawardena, The Emerging Internet of Things Marketplace From an Industrial Perspective: A Survey, IEEE Transactions on Topics in Computing, 2015, vol. 3. no. 4. pp. 585 - 598.

[4] Ovidiu Vermesan, Peter Friess, Internet of Thing- From Research and Innovation to Market deployment.

[5] Shifeng Fang, Li Da Xu, Senior Member, IEEE, Yunqiang Zhu, Jiaerheng Ahati, Huan Pei, Jianwu Yan, and Zhihui Liu, An Integrated System for Regional Environmental Monitoring and Management Based on Internet of Things, IEEE Transactions on Industrial Informatics, 2014, vol. 10, no 2, pp. 1596 - 1605.

[6] Younggi Kim, Younggi Lee Dept. of Computer Science KAIST Daejeon, Republic of Korea, "Automatic Generation of Social Relationships between Internet of Things in Smart Home using SDN-based Home Cloud".IEEE 29th International Conference on Advanced Information Networking and Applications Workshops, 2015, pp. 662 - 667, DOI: 10.1109.

[7] Z. Shelby, K. Hartke, and C. Bormann, RFC 7252: The Constrained Application Protocol

[8] J. Gettys Compaq/W3C, J. C. Mogul Compaq, H.Frystyk W3C/MIT, L. Masinter Xerox, P. Leach Microsoft, T. Berners-Lee W3C/MIT, June, 1999,RFC 2616: Hypertext transfer protocol.

[9] Walter, Kris, Niccolo, Bogdan and Virgil Dept. of Electronics and information Belgium, "Evaluation of constrained application protocol for wireless sensor networks", 18th IEEE Workshop on Local \& Metropolitan Area Networks (LANMAN), 2011, pp. 1-6.

[10] Berta Carballido Villaverde, Dirk Pesch; Rodolfo De Paz Alberola, Szymon Fedor, Menouer Boubekeur united technologies research centre Ireland, “ Constrained Application Protocol for Low Power Embedded Networks: A Survey", Sixth IEEE International Conference on Innovative Mobile and
Internet Services in Ubiquitous Computing (IMIS), 2012, pp. 702-707.

\section{Author Profile}

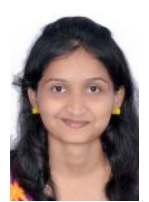

Swatee D. Sonawane Currently she is pursuing her masters in Computer Engineering at STESs Smt. Kashibai Navale College of Engineering, Pune. She has obtained his B.E in Computer Technology from Nagpur University, India. Research Area: IoT.

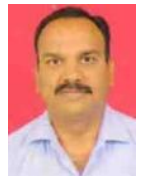

Vinod V. Kimbahune He is Assistant Professor in Department of Computer Engineering at STESs Smt Kashibai Navale College of Engineering, Pune, India. He has obtained his B.E and M.E degree in Computer engineering form Savitribai Phule Pune University, Pune, India. Currently he is pursuing his Ph.D. in Computer engineering form Savitribai Phule Pune University, Pune, India. Research Area: Next Generation Internet, Networking and Wireless Network. 